\title{
Commentaries on Top-Cited Boundary-Layer Meteorology Articles
}

\author{
John Garratt ${ }^{1}$ - James Wilczak ${ }^{2}$ - Albert Holtslag ${ }^{3}$ - Hans Peter Schmid ${ }^{4}$. \\ Andrey Grachev ${ }^{2}$. Anton Beljaars ${ }^{5}$. Thomas Foken ${ }^{6}$. Fei Chen ${ }^{7}$. \\ Christopher Fairall $^{2}$. Bruce Hicks ${ }^{8}$. Hiroyuki Kusaka ${ }^{9}$ - Alberto Martilli ${ }^{10}$. \\ Valéry Masson ${ }^{11}$. Matthias Mauder ${ }^{4}$. Steven Oncley ${ }^{7}$. Mathias Rotach ${ }^{12}$. \\ Michael Tjernström ${ }^{13}$
}

Published online: 29 August 2020

(c) Springer Nature B.V. 2020

\section{Introduction}

Brief critiques are given for:

1. Articles related to flux-gradient relations and eddy-correlation measurements, viz. Dyer (1974), Louis (1979), Moore (1986), Wilczak et al. (2001), Finnigan et al. (2003; together with Finnigan 2004).

2. Articles related to PBL modelling, viz. Deardorff (1980) and Troen and Mahrt (1986).

3. Articles related to urban meteorology, specifically urban canopy schemes, viz. Masson (2000), Kusaka et al. (2001), and Martilli et al. (2002).

These actually provide an interesting and very informative glimpse of the historical development of techniques that underpin key components of contemporary measurement and

\footnotetext{
John Garratt

jrgarratt@optusnet.com.au

1 CSIRO, Melbourne, Australia

2 NOAA, Boulder, CO, USA

3 Wageningen University, Wageningen, The Netherlands

4 KIT, Garmisch-Partenkirchen, Germany

5 ECMWF, Reading, UK

6 University of Bayreuth, Bayreuth, Germany

7 NCAR, Boulder, CO, USA

8 Metcorp, Norris, TN, USA

9 University of Tsukuba, Tsukuba, Japan

10 CIEMAT, Madrid, Spain

11 Meteo-France, Toulouse, France

12 University of Innsbruck, Innsbruck, Austria

13 MISU, Stockholm, Sweden
} 
numerical methodologies. Several of these articles complement others that appeared in other journals-we have in mind one that JRG was closely associated with, viz. Webb et al. (1980) regarding the influence of density fluctuations on measured eddy covariances. Another is associated with the pioneering numerical investigations of James Deardorff on the neutral and unstable planetary boundary layers, with and without clouds, viz. Deardorff (1972).

Unfortunately, not all invited contributions arrived in good time, and in the spirit of Corporal Jones' "Don't panic, don't panic" (refer BBC TV, circa 1970) JRG asked, at short notice, the authors of Wilczak et al. (2001), Masson (2000), and Martilli et al. (2002) to submit short comments on their own articles. They rose to the challenge, and are included, even though Hans Peter Schmid's critique of Wilczak et al. (2001), Finnigan et al. (2003), and Finnigan (2004) arrived just in time to be included!

For practical purposes, acronyms (e.g., MOST) and initialisms (e.g., NWP) are defined here for use in all commentaries. Some are not defined at all, but may be found in the appropriate reference (e.g., COARE, KEYPS). I mention: LES = large-eddy simulation, MOST $=$ Monin-Obukhov similarity theory, NWP $=$ numerical weather prediction, $\mathrm{PBL}=$ planetary boundary layer, TKE $=$ turbulence kinetic energy.

\section{Article: Louis (1979)—by A Beljaars, AAM Holtslag, and M Tjernström}

In the 1970s, a cooperative European project was initiated to improve numerical weather prediction with emphasis on the medium range. The European Centre for Medium-Range Weather Forecasts (ECMWF) was created to develop a state-of-the-art global model and to run it operationally on high-performance computers up to a forecast range of ten days. It was in this context that J-F Louis developed a scheme for turbulent diffusion and atmosphere-surface exchange that became very popular. Earlier, atmospheric models had very poor vertical resolution, so schemes that resolved the PBL were hardly feasible. Instead, bulk schemes, where the boundary layer was replaced by bulk transfer coefficients, or models with a prognostic equation for the daytime mixed-layer depth were used.

Louis (1979) — henceforth L79 — did not use a bulk scheme, but rather chose a scheme where the turbulent boundary layer was described by diffusion coefficients on a vertical grid, although the resolution in the PBL was still very limited (15 levels, at 30, 240, 640, 1230, 2000, ... m). L79 argued that for NWP the surface interaction with fast changing weather patterns is crucial and therefore a bulk approach is too restrictive and might not provide the necessary feedbacks. For instance, during a frontal passage, the complex dynamical structure might be lost with a bulk model. The choice of diffusion coefficients for vertical exchange turned out to be visionary, not the least because computer technology developed very rapidly and the increase of vertical resolution over time gave immediate benefits. The current ECMWF model has 137 levels in the vertical, with seven levels below $200 \mathrm{~m}$ and about $100-\mathrm{m}$ resolution at $1000 \mathrm{~m}$ above the surface. L79 further concludes that it is not sufficient to have turbulent diffusion dependent on shear, but a dependency on stability is absolutely crucial. A further advantage is that free shear layers, e.g., near jet streams, are handled automatically (at least qualitatively). Other design considerations were that the scheme had to be computationally cheap, and that the number of empirical coefficients had to be small for easy optimization.

At this time, MOST was well known and documented (e.g., Dyer 1974). Thus, MOST was the obvious choice for the so-called surface layer. Also, from the numerical point of view, this was a sensible approach, because profiles have a large curvature near the surface and the integral MOST profile functions represent nature very well. These profile functions 
can be seen as numerical finite elements in the discretization of the layer below the lowest model level, which is particularly important in models with limited vertical resolution. Monin-Obukhov similarity theory leads to an implicit expression for fluxes, but formally transfer coefficients can be expressed as a function of the bulk Richardson number. Instead of solving this iteratively, as current models often do, Louis decided to use empirically fitted functions for computational speed. Interestingly, L79 paid great attention to a proper matching in the stability functions between unstable and stable conditions, which was not the case in the original Kansas formulations.

The choice above the surface layer was more controversial because L79 decided to simply extend MOST above the surface layer, as if it applies locally. Many boundary-layer meteorologists must have been critical of this. At the time of publication, many aspects of the unstable PBL were already known (e.g., mixed-layer dynamics, PBL top entrainment, and counter-gradient effects). This was before FTM Nieuwstadt launched the idea of "local scaling" for the stable PBL in 1984. For fully turbulent stable PBL he suggested that MOST also applies to the outer layer, provided that surface fluxes are replaced by local fluxes. This was in fact already implicit in the Louis formulation.

So, what are the shortcomings of the Louis scheme? First of all, there has been controversy about the stability functions, because in NWP and climate models they are often very different from MOST observations. One of the strengths of the Louis scheme has here become a weakness. Synoptic-scale variability is profoundly sensitive to the deposition of momentum by many subgrid-scale processes, such as gravity-wave processes and subgrid-scale orography, which were poorly represented in early coarse-resolution NWP models. Hence, the stability functions were used for tuning, and errors were therefore introduced to compensate for, for example, unrealistic land-surface parameters or subgrid orography. Also, the lowwind-speed regime may have large errors in surface fluxes and near-surface temperature. It is now understood that, in both the stable and unstable regimes, interaction exists between large eddies or mesoscale variability and surface fluxes that is not represented by traditional MOST scaling, but also that this tuning has often resulted in an overly diffusive system. This has caused unrealistic dissipation of low clouds, erosion of low-level jets, and a PBL that is too deep.

Another issue is that the Louis scheme cannot reproduce PBL-top entrainment by convection. The latter is dominated by the diffusion of TKE from the bulk of the mixed layer into the inversion and this mechanism is not represented by the Louis scheme. Finally, the Louis scheme, being truly local, can only transport down-gradient, so that counter-gradient effects are not simulated. This was already commented on in the original paper, and it was correctly pointed out that counter-gradient effects are usually small (i.e., leading to small tilting of the mixed-layer profiles), and as long as the diffusion coefficients are large the profile will remain "well-mixed".

In most current models, the Louis scheme is no longer used in the unstable regime, mainly because it cannot represent buoyancy-driven entrainment. Many models now use the TKE equation or a scheme in which the mixed layer is diagnosed, and the diffusion coefficients are prescribed as a profile including diffusion in the inversion layer. In some models a Louis-type closure has been combined with mass-flux schemes for the convective PBL into so-called eddy-diffusivity mass-flux schemes. Specification of counter-gradient effects through an explicit flux term is also quite common. In the stable regime the Louis scheme remains very popular, for two reasons: (i) it has a basis in "local scaling" for the fully turbulent regime, (ii) it is simpler to optimize stability functions to compensate for model deficiencies than in more complex schemes (although mixing that is too strong often occurs). 
One may wonder how a scheme introduced in the 1970s can still have such an impact. Although substantial progress has been made, it is indeed remarkable that so many boundarylayer issues in climate and NWP models are still unresolved (e.g., Holtslag et al. 2013). One may ask if we should not have been able to come up with something better, with improved understanding of the dynamics of the turbulent boundary layer through new field experiments with modern instrumentation, the growing use of large-eddy simulation and lately even direct numerical simulation. With growing computational power in the $1980 \mathrm{~s}$, it was believed that higher order closure, where prognostic equations are carried for second and eventually higher order terms, would render first-order closure obsolete. As closure assumptions were pushed to higher and higher order terms the problem would solve itself. Eventually, however, it was realized that little was gained and, besides, the closure assumptions for higher moments were more complicated than expected.

Indeed, many seemingly more sophisticated PBL schemes have been tested for NWP models and were almost always punished by degrading forecast scores, not just for subtle parameters but also for more fundamental diagnostics related to synoptic-scale dynamics. Although itself being a small-scale process, PBL turbulence acts globally, cuts across scales, and affects dynamics at all scales including the general circulation and in particular the NWP scales. While the understanding of PBL turbulence can be based on highly accurate measurements, much uncertainty remains due to the effects of heterogeneous terrain and mesoscale variability (Mahrt 2011). Other processes such as drag/blocking from subgrid orography and vertical transport by convection also affect the momentum budget (Sandu et al. 2013). The latter is poorly known and cannot be reliably observed. As long as our understanding of the momentum budget is limited, we are left with incomplete models that must be tuned. Then easily tuneable, but sufficiently adequate, schemes have an advantage, and in this lies one of the strengths of the Louis scheme.

In conclusion, as a methodology, L79 is still the scheme of choice for the surface layer, but the future of this scheme in the outer layer is less clear. In stable stratification it is still widely used, but it may be gradually phased out once solutions are found for the momentum budget issues and for the interaction with mesoscale variability.

\section{Article: Dyer (1974)—by AA Grachev and CW Fairall}

According to MOST, the non-dimensional vertical gradients of mean wind speed, $U$, and potential temperature, $\theta$, can be written respectively as

$$
\varphi_{m}(\xi)=\left(\frac{\kappa z}{u_{*}}\right) \frac{d U}{d z}, \quad \varphi_{h}(\xi)=\left(\frac{\kappa z}{\theta_{*}}\right) \frac{d \theta}{d z},
$$

where $u_{*}$ is the friction velocity, $\theta_{*}=-\overline{w^{\prime} \theta^{\prime}} / u_{*}$ is the turbulent temperature scale, $z$ is height, $\xi=z / L$, where $L$ is the Obukhov length, and $\kappa$ is the von Kármán constant. It is often assumed that the universal function $\varphi_{h}$ can be used for scalars in general.

The exact forms of the universal functions in (1) in general are not predicted by MOST and must be determined from field experiments. However, MOST does predict the asymptotic behaviour of these functions under very stable $(\xi \gg 1)$ and extremely unstable stratification (free convection, $\xi \ll-1$ ). The forms of (1) have been discussed extensively during the past sixty years, and perhaps the so-called Businger-Dyer profile functions are the most widely and routinely used (Dyer 1967; Dyer and Hicks 1970; Businger et al. 1971; Hicks 1976). A 
historical note (Businger 1988) describes the circumstances that led to the Businger-Dyer relationships. The classic formulation suggests

$$
\varphi_{m}(\xi)=\left(1-\gamma_{m} \xi\right)^{-1 / 4}, \quad \varphi_{h}(\xi)=\left(1-\gamma_{h} \xi\right)^{-1 / 2},
$$

for unstable (convective) conditions $(\xi<0)$, and

$$
\varphi_{m}(\xi)=1+\beta_{m} \xi, \quad \varphi_{h}(\xi)=1+\beta_{h} \xi,
$$

for stable stratification $(\xi>0)$. Dyer (1974) compared the various flux-profile formulations and concluded that the numerical coefficients $\gamma_{m}=\gamma_{h}=16$ in (2) and $\beta_{m}=\beta_{h}=5$ in (3) provided by Dyer and Hicks (1970) are more preferable than those suggested by Businger et al. (1971) based on the data collected during the landmark 1968 Kansas field experiment. Furthermore, Dyer (1974) indicated that the von Kármán constant $\kappa=0.41$ in (1) is more convincing and generally accepted than $\kappa=0.35$ found by Businger et al. (1971), later confirmed by, e.g., Högström (1988). The numerical coefficients in (2)-(3) suggested by Dyer and Hicks (1970) and Dyer (1974) are now accepted as canonical values, implying that the turbulent Prandtl number $\operatorname{Pr}_{t}=\varphi_{h} / \varphi_{m}=1$ in neutral stratification. The functions for unstable stratification are derived, inter alia, on the assumption $R i=\xi$, where $R i=\xi \varphi_{h} / \varphi_{m}^{2}$ is the gradient Richardson number.

Although relationships (2) fit the available experimental data well for $-1 \lesssim \xi<0$, they do not obey the correct free convection limit $\varphi_{m} \propto \xi^{-1 / 3}$ and $\varphi_{h} \propto \xi^{-1 / 3}$ for $\xi \rightarrow-\infty$, which may lead to results that are not physically reasonable. Fairall et al. (1996) for the COARE bulk flux algorithm proposed to interpolate between the Kansas and the free convection formulae to avoid the undesirable feature for $\xi \rightarrow-\infty$. This approach gives good agreement with the standard Businger-Dyer formulation for near-neutral stratification and obeys the correct free convection limit.

In the case of stable stratification, the functions (3) are, in fact, a simple linear interpolation ("log-linear law") (e.g., Zilitinkevich and Chalikov 1968; Webb 1970) that provides blending between neutral and very stable cases. In the very stable case $(\xi \gg 0)$, MOST predicts that $z$ ceases to be a scaling parameter, that is, various quantities become independent of $z$. This limit requires that $z$ cancels in (3), which leads to linear relationships for the stability functions (2): $\varphi_{m}=\beta_{m} \xi$ and $\varphi_{h}=\beta_{h} \xi$. During the 1970s, this was termed "local $z$-less stratification", i.e., local-height-independent.

Another problem is associated with the behaviour of functions (3) in very stable conditions. Although both functions follow the $z$-less predictions for $\xi \rightarrow+\infty$, the $z$-less concept itself was questioned based on analyses of extensive datasets for stronger stability, including the limit of very stable stratification. Several studies reported that the stability functions (2) increase more slowly with increasing stability than predicted by the linear Eq. (3). To remove this ambiguity, Grachev et al. (2013) argued that the applicability of MOST is limited by the constraints imposed on the gradient and flux Richardson numbers $R i<R i_{c r}$ and $R f=\xi / \varphi_{m}<R f_{c r}$, where both critical values $R i_{c r}$ and $R f_{c r}$ are about $0.20-0.25$. Imposing this prerequisite (i.e., separating data points into subcritical and supercritical cases) shows that the data follow classical Businger-Dyer profiles (3) and are consistent with the $z$-less scaling after the irrelevant cases have been filtered out.

Why is Dyer (1974) highly cited, and what has been its value to the scientific community? A quick answer is that "it just happened to be in the right place at the right time"; however, there is a longer answer to this question. First, flux-profile relationships (as well as bulk flux algorithms) are widely demanded by the meteorological community in general. Second, the Businger-Dyer relations draw on underlying physical principles (e.g., a mixing-length 
model and the $z$-less scaling); that is, Eqs. 2 and 3 are not just simple empirical formulae. In addition, Eqs. 2 and 3 are elegant and Dyer (1974) suggested the generally accepted numerical coefficients such as $\kappa \approx 0.4, \operatorname{Pr}_{t}(0)=1$, and $\beta_{m}=1 / R f_{c r}=5$. Finally, the influence of JA Businger and AJ Dyer in micrometeorology has played an important role in this matter. Though, subsequently, several alternative empirical forms and different approaches have been proposed for the MOST universal functions (1), Businger-Dyer type functions have stood the test of time and are still widely used.

\section{Article: Dyer (1974)—by BB Hicks}

I shared an office with Arch Dyer for many years, and I learned to read between his lines. In this respect, examination of his 1974 paper is illuminating — three key issues need emphasizing.

Issue 1: the experimental work at Kerang and later at Hay had two main purposes. Bill Swinbank's initial goal was to obtain support for his exponential wind profile (Swinbank 1964). Arch Dyer did not have a theory to test. His intent was to measure covariances and then to see where the results led him. The methods first used were incapable of measuring the momentum covariance, and so the values of $u_{*}$ required to test Swinbank's expectations were derived indirectly. At the same time, the KEYPS profile (referred to as the "PESKY" profile at Aspendale) was favoured elsewhere (Panofsky 1963). In essence, Arch refuted the KEYPS profile. Swinbank's exponential wind profile was an outlier. Subsequently, it was determined that his earlier analysis of field data (Swinbank 1964) applied a friction coefficient to wind speeds measured at the wrong height. Arch's introductory mention of Swinbank's early work is an indication of a fellowship that endured many professional differences and repeated billiards and snooker games at the lubricated establishments favoured for evening recreation during field studies.

Issue 2: there is a subtle hint of Arch's insecurity about the log-linear stable relationship, namely that non-conforming data "may be due to the normal statistical variation of atmospheric behaviour" and should not be dismissed. Another close colleague was promoting the log-linear formalism, but with the lack of measured eddy fluxes (Webb 1970). The stable case was not investigated in the same way as the unstable case because, (i) sufficiently reliable data were difficult to obtain, and (ii) the field work required payment of overtime.

Issue 3: when the first main results of the Kansas field experiment appeared (Businger et al. 1971), the claim that the von Kármán constant was 0.35 caused considerable concern. Arch observed that if the Kansas drag-plate results were used as a reference and the eddy fluxes adjusted to fit, then the discrepancy would disappear. Wieringa (1980) showed that tower shadowing was a likely cause of such an error. To this day, Kansas presents, as Arch says, "a difficulty which calls for considerable clarification".

The Dyer (1974) paper was a timely shift from a theoretical focus in the absence of data to an experimental approach to help advance the theory. In the following years, there have been many relevant field experiments, but the shift in focus was Arch's.

\section{Article: Moore (1986)—by T Foken, MW Rotach, and M Mauder}

Moore (1986) - henceforth M86 - is not a fundamental paper on the frequency response of sensors, but rather is one of the first to give practical guidance for the correction of the high 
frequency energy loss of turbulence measurements. Its value must be considered in relation to the history of the development of the eddy-covariance technique.

With the beginning of eddy-covariance measurements around 1960, when the first sonic anemometers and fast response sensors became available, several fundamental papers about the frequency correction were written (Gurvich 1962; Hicks 1972; Horst 1973; Kristensen and Jensen 1979). At that time only a few groups were able to realize eddy-covariance measurements and these groups developed their own correction schemes. In the beginning of the 1980s, digital computer and storage technique experienced a stage of development that made continuous measurements and data analysis possible even under field conditions. At that time, the Institute of Hydrology in Wallingford, UK, developed a sonic anemometer and a flux measurement system (Shuttleworth et al. 1982) that was later used in an experiment in Brazil and called "Hydra". This was one of the first complete descriptions of a battery-based flux-measurement system, upon which, in fact, M86 was written.

The paper deals with the correction due to the low-pass filtering of the sensor system. The relative error, $\Delta F / F$, on the fluxes due to frequency, $f$, losses may be computed according to

$$
\frac{\Delta F}{F}=1-\frac{\int_{0}^{\infty} C_{w s}(f) T(f) d f}{\int_{0}^{\infty} C_{w s}(f) d f}
$$

where $C_{w s}(f)$ is the ideal cospectral density and $T(f)$ is the apparatus transfer function. This is a usual method in metrology and was already applied by Horst (1973) on flux measurements. Using the properties of the Laplace transform, the transfer function of a complex system can be determined as the product of the single transfer functions such as the dynamic response of the sensor (time constant), line averaging of the sensor path, sensor separation, and effects of the electronic unit. And this is what was proposed by M86. This offers the possibility to construct for each turbulence moment (such as the variance or covariance) the individual transfer function as a combination of a set of transfer functions. The transfer functions of eddy-covariance systems are in a wide range of frequencies close to unity and differences from the ideal spectra occur mainly in the inertial subrange, where a clear reduction of the energy according to the Kolmogorov laws is given. The step in the direction of a real-time correction of the energy loss for high frequencies was taken by M86 with the application of model spectra as presented by Kaimal et al. (1972), and this is the novelty of Moore's paper. This is much more practical to handle than using individual spectra and their extrapolation to the inertial subrange. For the transfer functions, M86 used already published formulations from Gurvich (1962), Hicks (1972), and Kristensen and Jensen (1979). Even though M86 was written for the Hydra system, most parts of the correction method can be easily applied for other systems.

In the following decades the frequency correction by M86 became a standard method used in most of the eddy-covariance software packages. Several updates were made: the simple transfer function for the lateral separation was partly replaced, a transfer function for tubes of closed path systems was added, and it was determined that the aliasing correction should not be performed. Other correction methods, such as the correction according to an electronic damping circuit (Eugster and Senn 1995) proved not so successful, while the method by Moncrieff et al. (1997) and Horst (1997), with a slightly different set of model spectra and transfer functions, is still in use. This latter approach was recently compared with the M86 approach and differences of about $1 \%$ were reported.

Moore (1986) is cited by all those authors who very carefully describe how they calculate the turbulent fluxes, and remains a key paper in textbooks and other documents on the eddy-covariance method. It seems that there is no need to update the correction scheme fundamentally. 


\section{Articles: Wilczak et al. (2001), Finnigan et al. (2003), Finnigan (2004)_by HP Schmid}

In the late 1980s, observation-based estimates of the global carbon cycle indicated that a substantial "missing sink" of atmospheric $\mathrm{CO}_{2}$ was likely attributable to a net carbon uptake by terrestrial ecosystems (Tans et al. 1990). This missing sink problem called for extensive long-term observations of net carbon exchange over all major terrestrial biomes. The first successful attempts at observing $\mathrm{CO}_{2}$ fluxes by eddy-covariance continuously over a year or more were undertaken at Harvard Forest, starting in 1990, and lead to the rapid growth of flux sites coordinated in the global program FLUXNET (Baldocchi et al. 2001). The ensuing establishment of eddy covariance as the measurement technique of choice to derive observation-based estimates of net ecosystem-atmosphere exchange of $\mathrm{CO}_{2}$ (and increasingly other gas species) hinged on several developments that converged in the late 1980s and 1990s (Baldocchi 2013): (i) through technical advances, sonic anemometers and infrared gas analyzers (for $\mathrm{CO}_{2}$ and $\mathrm{H}_{2} \mathrm{O}$ ) became both more reliable and affordable; (ii) computing and data storage technology opened the way for storing and processing virtually unlimited data streams at high sampling rates even in remote locations; and (iii) advances in micrometeorological theory led to tools of data quality assurance and quality control that form the basis for eddy-covariance applications in the "real world" (e.g., Lee et al. 2004).

The real world, where long-term eddy-covariance observations are needed, is not flat, not uniform, and not stationary. Real instrumentation is not perfect, and the two main components of scalar EC flux estimates (vertical velocity and the scalar mixing ratio) are often not perfectly synchronized, and exhibit discrepancies in temporal and spatial reference and resolution.

Here, we highlight important contributions to our understanding of vertical velocity in non-stationary flows over complex terrain. The first of these, Wilczak et al. (2001; henceforth WOS01), proposes a practical solution to a common problem in the processing of long time series of raw eddy-covariance data. The others, Finnigan et al. (2003, Part I, henceforth FP1) and Finnigan (2004, Part II, henceforth FP2) present the theoretical framework of consequences on computed scalar fluxes by data processing operations such as averaging procedures or the anemometer tilt corrections proposed by WOS01 and others.

If the vertical instrument coordinate of a sonic anemometer is misaligned with the "true" vertical, the resulting vertical velocity signal is contaminated by a portion of the horizontal flow (and vice versa), dependent on the angle of the misalignment (e.g., McMillen 1988). Over flat and uniform terrain, the mean flow is essentially parallel to the terrain, so that mean vertical velocity vanishes. Thus, in ideal terrain this lemma serves as the guide to practical instructions for tilt corrections, to be applied to each eddy-covariance averaging period (commonly over 30-60 min).

In the real world, where aerodynamically non-uniform surfaces are combined with non-flat terrain, the above lemma does not apply. The angle between the mean flow (over an eddycovariance averaging period) and a fixed eddy-covariance system on a flux tower, depends on (i) the effective instrument height above the topography (modulated by seasonal changes in vegetation), (ii) thermal stratification of the flow, (iii) relative position of the flux tower in the terrain (e.g., ridge-top, valley bottom, distance to change in surface roughness), and the wind direction relative to the geometry of the terrain (see, e.g., Figures 1-3 in FP2). Even in such complex conditions, the standard short-term tilt correction procedure can be applied: for every averaging interval, the "vertical" direction is perpendicular to the local tangential plane of the average flow field, with zero mean vertical velocity. However, as WOS01 argue, non-stationary flow may cause the orientation of the reference coordinate 
system to change strongly from one averaging period to the next, and the sampling uncertainty can be large, especially towards the convective limit of low wind speed and strong instability. With lack of stationarity and homogeneity, ergodicity cannot be assumed, so that averages depend on the averaging operator used (e.g., FP1). Both WOS01 and FP1 point out that low frequency motions that cause such changes in apparent flow coordinates may contribute to actual transport but are cut out of eddy-covariance-derived fluxes by the averaging. This latter systematic bias is exacerbated in long-term flux programs. It is thus not surprising that the closely linked questions about vertical velocity determination, choice of averaging operator, and choice of coordinate system started to be hotly debated in the late 1990s and early 2000s (e.g., Lee 1999), when the number of long-term $\mathrm{CO}_{2}$-flux stations increased dramatically (Baldocchi et al. 2001). The first FLUXNET Workshop in 1998 was dominated by these topics, and the three articles highlighted here are not the only landmark papers that can be traced to discussions in that workshop and its follow-ups.

Interestingly, long-term scalar-flux observations were hardly mentioned in WOS01, but consequences of sensor misalignment on momentum flux estimates were discussed and are readily transferrable to scalar fluxes. [Note from the co-editor: the effect of tilt errors on the wT covariance is mentioned on p.135 and p.147 of their paper.] WOS01 discuss the wellknown double- or triple-rotation corrections and the uncertainty introduced by changing rotation angles from one data run to the next in non-stationary conditions. This problem leads them to propose a pragmatic new method to align the vertical axis of turbulence to the normal of a plane that is locally tangential to the long-term flow (e.g., above a slope) over several data runs. Because this plane is found by multiple linear regression of the measured velocity components, they term it the planar-fit method. Over complex terrain and nonstationary conditions, this method is commonly applied in a variant (modified planar fit), where the orientation of the tangential plane is allowed to vary dependent on the azimuth of the horizontal flow.

WOS01 were not the first to propose a stochastic method to find a tilt angle correction (see, e.g., Lee 1998 or Paw et al. 2000 and references therein). We can only speculate on the reasons for the wide and continuing reception and recognition of WOS01: first, they compared the different methods quantitatively, in terms of uncertainty; second, they coined the term "planar fit", which is easily remembered; third, they provided a program code (Matlab) that facilitates adoption of the planar-fit method.

FP1 and FP2 examine assumptions and methods associated with eddy-covariance-flux measurements in light of common problems to close the observation-based energy- or mass balances at sites over complex terrain with tall vegetation. Following a mostly conceptual and theoretical approach, they focus on the influence of data analysis procedures from raw turbulence data to common 30-min or 60-min estimates on the computed mass balance.

FP1 emphasize the links between common block-averaging operators and coordinate rotations used on raw data. In their words: "the particular averaging operation that is applied to the instantaneous flow field determines what part of the velocity will be treated as 'mean flow' and what as turbulence. The mean flow may then be used to determine the orientation of the coordinate frame". They demonstrate that coordinate rotation on every averaging period constitutes a high-pass filter operation that reduces the magnitude of the computed eddy-covariance fluxes systematically. They conclude that the planar-fit method of WOS01 is preferable to short-term rotation from a mass-balance perspective.

FP2 observes that the streamline coordinate system most convenient to the experimentalist is usually local (referring to the location of the eddy-covariance system) and variable in time. This is in stark contrast to coordinates used in flow and transport models, which are usually 
terrain following and are thus neither locally defined nor time dependent. Reconciliation of the observational and modelling coordinate systems is not simple.

While the primary attraction of WOS01 is its practical instructions to users in the micrometeorological community, FP1 and FP2 read more like a chapter in an advanced textbook. Their strength, and likely their attraction leading to frequent citations, lies in their comprehensive and conceptually thorough treatment of the subject matter, combined with highly instructive, yet simple and clear, graphics.

\section{Article: Wilczak et al. (2001)—by JM Wilczak and SP Oncley}

[This critique was provided by two of the authors (JMW and SPO) rather late in the proceedings at the request of the co-editor (JRG).]

Prior to the publication of Wilczak et al. (2001) — hereafter WOS01 — it is fair to say that the sensitivity of errors in sonic anemometer turbulence measurements to small tilt offsets in the anemometers was not fully appreciated. WOS01 provided an in-depth investigation of the effects of those tilts on the calculation of turbulence covariances, variances, and thirdorder moments. They demonstrated how for unstable stratification the resulting error in the momentum flux for a given tilt could be expressed as a function of stability and nondimensional PBL depth, with the largest errors occurring for strongly unstable stratification and deep boundary layers. They then evaluated three different techniques for correcting the unknown tilts: the double rotation method (the standard technique used prior to WOS01), the triple rotation method, and a method called the planar-fit technique, first developed by $\mathrm{S}$. Stage in the 1970s and used by NCAR since 1991 in support of research-community-led field programs. They demonstrated the weaknesses of the double- and triple-rotation methods. For the double-rotation method, sampling error of the mean vertical velocity results in a tilt angle estimation error that adds noise to the longitudinal stress estimate, increasing its uncertainty. In addition, they showed that the double-rotation method makes no correction for tilts in the lateral direction, leaving the measurement of the lateral stress potentially very uncertain. For the triple-rotation method the lateral stress is set to be zero by assumption, and sampling errors in the vertical velocity frequently result in large run-to-run estimates of the sonic anemometer tilts that are unphysical. It is noted that the double-rotation and triple-rotation techniques attempt to orient the sonic anemometer with the longitudinal component of the wind in a streamwise coordinate system, with deviations occurring due to sampling errors of the vertical velocity. In contrast, the planar-fit technique eliminates these shortcomings, and orients all three axes of the anemometer in the streamwise coordinate system. Subsequent to its publication, the planar-fit approach has been adopted as the standard processing method for the US National Ecological Observatory Network and as one of the standard methods for the Ameriflux network of carbon flux towers. The planar-fit technique also is a standard option in the data processing software provided by at least one instrument company (LI-COR Inc.'s EddyPro software). It should be noted that some of these networks use "segmented" planar fit for complex terrain sites, in which planes are evaluated separately for different wind direction sectors. The applicability of the planar-fit method to these non-planar sites has to be evaluated for each case. We note that WOS01 stated that in strongly sloping terrain buoyancy terms should be evaluated using a gravitationally-aligned vertical velocity, not a vertical velocity defined by planar fit. Due to the lack of cross-talk between the vertical velocity and a scalar variable, the buoyancy-flux error is small except for extreme tilt cases. However, the planar-fit technique allows one to recover low-frequency contributions to the 
scalar fluxes that are filtered out when using the double- or triple-rotation methods, and as demonstrated by Finnigan et al. (2003) this indirect effect can be much larger than the direct effect of the scalar-flux tilt correction, which justifies the use of the planar-fit method for the buoyancy flux.

\section{Article: Deardorff (1980)—by JM Wilczak and AAM Holtslag}

Jim Deardorff used both numerical models and observations throughout his illustrious research career. His early publications in the 1960s on numerical simulation dealt with relatively simple flows that could be studied in the laboratory, such as parallel-plate convection and channel flow. These were followed in the early 1970s by three-dimensional numerical simulations of the dry, cloud-free PBL, in which he developed techniques (later known as large-eddy simulation) to represent the largest energy-containing eddies and to parametrize the effects of subgrid-scale turbulence. The year 1976 saw the publication of several important papers on the cloudy boundary layer, either by Deardorff or by scientists influenced by Deardorff's work.

The first of these focussed on the advantages of using the liquid-water potential temperature as a model variable (as proposed by Betts 1973) for the three-dimensional modelling of solid and broken stratocumulus layers (Deardorff 1976a). Deardorff (1976b) concerned the stratocumulus-topped mixed layer in which he utilized the Lilly (1968) vertically integrated mixed-layer equations to investigate the impacts of cloud-top entrainment. Then, with Deardorff's guidance, Sommeria (1976) incorporated equations for liquid water into Deardorff's three-dimensional turbulence model and simulated a trade-wind boundary layer with shallow cumulus. Sommeria and Deardorff (1977) described subgrid-scale condensation in that same model.

Finally, Deardorff (1980) — hereafter D80 — focussed on stratocumulus-capped mixed layers derived from a three-dimensional model, whose long-standing importance is due to several factors. First is the importance of stratocumulus clouds in the Earth's radiation balance. D80 also introduced new concepts for both stratocumulus and for PBL scaling, and utilized new modelling techniques that formed the basis of later LES models of both cloudy and dry boundary layers. At the time, LES was in its infancy, but became an extremely popular and effective tool for investigating not only PBL dynamics but with many other applications to the lower atmosphere. The main features of D80 can be summarized as follows:

(i) a review of the modelling of stratocumulus clouds, emphasizing the mixed-layer model of Lilly (1968) and its assumptions;

(ii) the three-dimensional model equations, including the use of Betts' liquid-water potential temperature as a thermodynamic variable, and the prescribed radiative flux divergence in terms of magnitude and height for each model grid column;

(iii) a new and simpler subgrid turbulence parametrization scheme in which the subgrid eddy coefficient is proportional to the square root of the subgrid turbulence intensity. As noted by LeMone et al. (2019), this accounted for the effects of pressure fluctuations and turbulent transport as well as buoyancy, shear, and dissipation on the eddy coefficient, and later came to be called the Deardorff TKE scheme (Moeng and Sullivan 2015);

(iv) a 2-km deep domain, with $40 \times 40 \times 40$ gridpoints, with a vertical grid spacing of $50 \mathrm{~m}$ set by the limit of computer resources at the time. 
D80 considers seven cases, including a dry PBL, a "dry cloud", a stratocumulus layer with no radiative cooling, and finally realistic stratocumulus with cloud-top radiative cooling, all with a specified PBL depth of between 1 and $1.5 \mathrm{~km}$. Major results include:

(i) even with the relatively coarse resolution of the model, the subgrid entrainment was no more than about $20 \%$ of the total, allowing for the entrainment process to be reasonably accurately analyzed in his simulations;

(ii) the ease with which the entrainment of dry air exceeds the surface evaporation for this PBL depth appears to be the reason why deep stratocumulus layers rarely reach the surface, and why surface-based fog is generally much shallower;

(iii) the usefulness of the generalized convective velocity scale $w_{*}$, based on the vertical integral of the buoyancy flux, for scaling turbulence statistics is demonstrated;

(iv) the elucidation of entrainment processes in the cloudy boundary layer, developing entrainment rate scaling laws based on $w_{*}$, or on the standard deviation of the vertical velocity at the PBL top, both as a function of buoyancy Richardson number.

Importantly, D80 laid out many areas of future research: the obvious need for increases in model resolution to reduce truncation errors and better resolve the entrainment process; specification of radiative cooling that is dependent on cloud-water content, and not fixed; a less stringent critical Richardson number allowing for greater subgrid-scale turbulence in and above the capping inversion; and the impact of mesoscale variability on the stratocumulus layer.

D80 has often been cited in the development and evaluation of numerous modelling systems: RAMS, COAMPS, ARPS, JMA, WRF-Fire, HIRLAM, ICON, coupled atmosphere ecosystem/biosphere models, and general circulation models; and in relation to LES used to develop simpler parametrizations, such as eddy diffusivity profiles, counter-gradient and non-local mixing approaches, higher-order turbulence closures, mass-flux-based turbulence parametrizations, and bulk microphysical schemes. The results from D80 have been used to interpret aircraft observations of the stratocumulus-capped PBL, and in radar-observationbased retrievals and for developing assimilation methods. Clearly, the influence of D80 has spread far and wide through almost all areas of meteorology, and to many other disciplines as well. We thank Chris Fairall for a helpful discussion on the importance of the Deardorff paper.

\section{Article: Troen and Mahrt (1986)—by AAM Holtslag and JM Wilczak}

Troen and Mahrt (1986) — henceforth TM86 — deals with "a simple formulation of the boundary layer for use in large-scale models and other situations where simplicity is required". Here we briefly review and analyze its main impacts. As mentioned by TM86, their formulation of the PBL "was intended for use in models where some resolution is possible within the boundary layer, but where the resolution is insufficient for resolving the detailed PBL structure and overlying capping inversion".

In retrospect, TM86 appeared at a very opportune moment. Until the 1980s, the formulation of the PBL in large-scale models for weather and climate was mostly based on simple Ktype flux-gradient approaches, or on bulk descriptions of the entire boundary layer. Due to increased computer power, higher resolution became possible, but it was still insufficient to resolve the PBL in detail. 
Based on earlier work by Deardorff (1966) and others, TM86 write the turbulence flux $\overline{w \theta}$ of potential temperature $\theta$ in an unstable boundary layer as

$$
\overline{w \theta}=-K_{h}(\partial \bar{\theta} / \partial z-\gamma) \text {. }
$$

Here $K_{h}$ is the eddy diffusivity for heat, $\partial \bar{\theta} / \partial z$ is the local mean vertical temperature gradient, and $\gamma$ is the so-called counter-gradient term. The latter is related to the bulk properties of the unstable PBL, e.g., the surface (virtual) heat flux, a turbulence velocity scale $w_{s}$, and the PBL depth $h$. The turbulence velocity scale is basically related to the friction velocity and the Deardorff convective velocity scale.

Note that in the mid-part of a convective boundary layer a small positive vertical temperature gradient typically is present, but the heat flux is significant and upwards. In a model this can be achieved by proper formulation of the combination of $K_{h} \gamma$ in (1). As such the latter is sometimes also referred to as the non-local heat-flux contribution (e.g., Holtslag and Moeng 1991). For the stable and the neutral PBL, the non-local heat flux term is set to zero. The eddy diffusivity $K_{h}$ is formulated in terms of a specified profile following, e.g., O'Brien (1970)

$$
K_{h} / w_{s} h=z / h(1-z / h)^{q} .
$$

TM86 experimented with $q=1$ and with $q=2$, but finally took the latter value. The cubic shape of the resulting profile was confirmed later by Holtslag and Moeng (1991) for the convective boundary layer on the basis of LES. For the stable boundary layer, it is also consistent with the local scaling for a quasi-stationary PBL. The PBL depth $h$ is expressed by TM86 in terms of a bulk Richardson number, which is modified to include the influence of rising thermals for the unstable case.

Many studies have made additional proposals for alternative descriptions and extensions of the PBL scheme described by TM86, in particular with respect to the impact of entrainment on the unstable PBL (e.g., Beljaars and Viterbo 1998), and extension of Eq. 1 for scalar mixing and for mixing in low-level clouds (Lock et al. 2000). Later, Frech and Mahrt (1995) also proposed and utilized the format of (1) for non-local momentum mixing.

The various formulations and flavours of the TM86 scheme have become quite popular in models for weather and climate on various scales. Holtslag et al. (1990) implemented the TM86 scheme in a short-range weather forecast model and found improved and realistic PBL profiles for temperature and moisture compared with the previously utilized bulk model. Subsequently, Holtslag and Boville (1993) used their implementation of the TM86 scheme in the NCAR Community Climate Model version 2 and noted that the scheme was able to mix moisture upwards from the surface much more efficiently and realistically than a local type mixing approach. This strongly affected the vertical heat transport by convective clouds.

Furthermore, Hong and Pan (1996) implemented the TM86 scheme in the MM5 mesoscale model, and Hong et al. (2006) updated the scheme for the WRF model and documented improved model results, which attracted many additional users. As noted by the latter authors the (updated) TM86 scheme showed important model skill improvements for precipitation forecasts over the continental United States and for monsoonal precipitation because of more realistic interactions of the PBL and cloud convection schemes. In addition, the TM86 scheme provided inspiration for updated model versions at many operational weather and climate centres, including ECMWF, the UK Met Office, the Korea Institute of Atmospheric Prediction Systems, NCEP, and the NOAA/Geophysical Fluid Dynamics Laboratory.

It seems that overall, the various versions of the TM86 scheme have been selected because, despite their simplicity, they provide for the development of a much more realistic well-mixed 
layer within the dry convective boundary layer. In particular, the choice of the diffusivity profile by Eq. 2 is important for the mixing of moisture away from the surface in unstable conditions, and the subsequent impact on convective clouds and precipitation. Overall the results for the stable boundary layer seem less beneficial, and future attention in this area is needed.

Finally, TM86 applied their scheme to study the evolution of the PBL for different ratios of surface evaporation to potential evaporation. They found that a typical variation of surface evaporation resulted in a much greater variation in PBL depth than that caused by the choice of the PBL depth formulation or other model details. Many additional studies have used the TM86 scheme to study and represent the complex interactions between the land surface and the lower atmosphere and the impacts on low-cloud formation (e.g., Pan and Mahrt 1987; Chen and Dudhia 2001; Ek and Holtslag 2004). Thus, the success of TM86 derives from its simple and pragmatic approach for representing an essential feature of the convective PBL in weather and climate models.

We thank Hua-Lu Pan who worked with the first author on the implementation of the TM86 scheme in the Air Mass Transformation model at KNMI (Holtslag et al. 1990). Michael Ek and Sukanta Basu are acknowledged for comments and suggestions.

\section{Articles: Masson (2000), Kusaka et al. (2001), Martilli et al. (2002)}

[The following critiques were provided by the three main authors (VM, HK and AM) rather late in the proceedings at the request of the co-editor (JRG)].

\subsection{Article: Masson (2000)—by V Masson}

The success of Masson (2000)—-hereafter M2000_can be linked to three types of issues: theoretical, operational, and societal.

First, M2000 is the first attempt to include the effect of cities in an atmospheric numerical model. It proposes an urban canopy scheme, Town Energy Balance (TEB), to simulate the specific energy and water exchanges between a city and the atmosphere. The three-dimensional nature of the urban fabric is also important, as it produces shadows, and significantly affects the radiation budget of the urban landscape. Since the 1970s, experimentalists in particular increased our understanding on the processes that influence the urban climate and create the urban heat island (Oke 1982).

M2000 provides a modelling methodology that allows the integration of relevant physical processes into a unique tool, by using the 'urban canyon' approach as a simplified, but still three-dimensional, geometry of the city, and by taking into account the important physical and hydrological processes. The objective here is to reproduce the essential details of the diurnal cycle of the surface energy balance. This methodology has subsequently been used in many urban canopy models (see a review in Garuma 2018).

Second, the TEB scheme has been included in many operational NWP models. With the increase in horizontal grid resolution in research versions to $100 \mathrm{~m}$ to $1 \mathrm{~km}$, and the need to include the meteorological impact of cities, operational NWP models at the kilometric scale were available by around 2010. The TEB scheme is now included in the AROME, ALARO, and HARMONIE models used by many European countries, as well as in the GEM Canadian operational model. The latter was used to forecast (at 250-m resolution) the meteorological conditions for Toronto, Canada, during the Pan American Games in 2015 (Joe et al. 2018). 
Third, the impact of urbanization on local weather and climate has become an increasing societal concern during the last 15 years. For example, the nocturnal urban heat island increases thermal discomfort and has sanitary consequences during heat waves, as was seen in European cities in 2003 (Laaidi et al. 2012). With urban impacts potentially enhanced by climate change, the topic of urbanization is now a priority of the World Meteorological Organization, increasing the need for interdisciplinary studies on the urban climate. This is a challenge, and because more societal-oriented impact studies and services are demanded, models must continue to evolve. This is the case for the TEB scheme. The interaction of urban vegetation (gardens, trees, green roofs) with the urban fabric provides the basis for nature-based solutions for the adaptation of cities to climate change (Lemonsu et al. 2012, Redon et al. 2017, de Munck et al. 2013).

A building energy module (Bueno et al. 2012; Pigeon et al. 2014), including consideration of human behaviour and building uses (Schoetter et al. 2017), makes it possible to evaluate changes in the energy consumption of buildings within sociological and urban-planning scenarios. Recently, a multi-layer description of the airflow between buildings comprising the urban canopy improved the forecast of air temperature within high-rise cities, as in Hong Kong (Schoetter et al. under review). To conclude, one can say that M2000 also contributed to the beginning of a large interdisciplinary adventure within the urban-climate scientific community and beyond.

\subsection{Article: Kusaka et al. (2001) - by H Kusaka and F Chen}

Kusaka et al. (2001) — henceforth K4-01—represented an important milestone in developing single-layer urban canopy models (SLUCM), and was the first attempt to compare hierarchical urban modelling systems, viz. a SLUCM, a slab urban model, and a multi-layer urban canopy model. The SLUCM described in K4-01 is conceptually similar to that in Masson (2000). It is an enhanced version of the SLUCM initially developed and described in Kusaka et al. (1999). The unique and hierarchical analysis conducted in K4-01 revealed a grand similarity between the SLCUM and a multi-layer UCM in simulating the diurnal variation of the heat and momentum fluxes, and the ability of such a model to correctly capture the diurnal cycle of the surface temperatures of roofs, walls, and roads in an urban canyon. In contrast, the slab model failed to capture features of the fluxes and surface temperature simulated in a multi-layer UCM despite the calibration of slab-model parameters. These results indicated that the SLUCMs performance is comparable to that of the multi-layer UCM, with the added benefit, at the time, of being computationally affordable. This opened up new opportunities for its application in real-time NWP models.

In 2005, the SLUCM, with minor improvements, was implemented into the public release of the WRF model (Kusaka et al. 2005). This filled an important gap in representing urban canopy processes in NWP models generally, and specifically in the WRF model that previously used a slab model only. In no time, the WRF-SLUCM modelling system has become the feature most in demand and has been widely used on urban topics such as the heat-island effect, extreme weather events, and on the impact of urbanization on regional precipitation, weather and climate, air quality, human health, and urban planning (Chen et al. 2011). Kusaka's SLUCM has also been implemented in other advanced research global and mesoscale models (e.g., the SCALE model developed by RIKEN). The world-wide success of the K4-01 modified SLUCM is primarily due to its elegant conceptualization, simplicity, numerical stability, and computational efficiency. 


\subsection{Article: Martilli et al. (2002) - by A Martilli}

Studying the urban atmosphere has been one of the motivations for the development of mesoscale atmospheric models since the 1970s (e.g., Bornstein 1975). However, around that time urban areas were represented simply as relatively (when compared to the surrounding countryside) rough and warm surfaces. No attempt was made to simulate features of the urban canopy itself. Then, Masson (2000), Kusaka et al. (2001), and Martilli et al. (2002) — henceforth MCR02_-presented new schemes that revolutionized the representation of urban areas in mesoscale models. A common feature was that for the first time an attempt was made to represent the urban canopy in the context of the mesoscale model, using a highly simplified representation of the urban morphology (essentially a collection of infinite canyons, all of the same geometry) for which separate energy budgets for vertical (walls) and horizontal (road, roof) surfaces were solved. In this way, radiation trapping and shadowing effects were accounted for. Specific parametrizations of the turbulent exchange between the urban canopy and the lower atmosphere were also included. These advancements were made possible essentially through three factors: (i) the large body of knowledge about the behaviour of the surface energy budget (Oke 1988) and turbulence characteristics (Rotach 1993) in urban areas, built up in the previous decades; (ii) the increase of computing power allowed for greater horizontal grid resolution; and (iii) the growing concern about air quality and thermal comfort issues in urban areas that motivated specific studies to evaluate different mitigation strategies. These three schemes, therefore, opened the way to new applications of mesoscale models when applied to the urban atmosphere.

In contrast to the approaches of Masson (2000) and Kusaka et al. (2001), the MCR02 urban surface-exchange scheme-later called the Building Effect Parametrization (BEP)—is "multi-layer"; this has the bottom of the atmospheric domain at street level, and not at the displacement height as in Masson (2000) and Kusaka et al. (2001), and can include several numerical levels within the urban canopy. Due to this, the sink of momentum due to flow around buildings is represented with a drag force, and the vertical turbulent transport within the canopy is solved by modifying the TKE conservation equation and the associated length scales, derived from the Bougeault and Lacarrere (1989) turbulence scheme. As shown in MCR02, this approach reproduces the typical vertical profiles of turbulent fluxes in the urban roughness sublayer, as well as the elevated nocturnal inversion often observed over urban areas. Its disadvantage is that it requires very high vertical resolution $(5-10 \mathrm{~m})$ close to the ground, and hence is computationally expensive. The advantage, on the other hand, is that it can reproduce the impact of the variability in building heights and is particularly suited to cities with neighbourhoods featuring very tall buildings. In fact, it has successfully been used to simulate the urban canopies of New York, Hong Kong, and Singapore. The scheme has been implemented in mesoscale models, such as the FVM, COSMO, and METRAS models, and the widely used WRF model.

The MCR02 canopy scheme formed the basis of several developments that took place in the following years, such as its inclusion in, (i) a simple building energy model (Salamanca et al. 2010), allowing, for the first time, study of the feedbacks between the urban climate and building energy consumptions; (ii) the first multi-layer scheme (BEP-Tree) that accounts for the impact of trees in the urban canyon (Krayenhoff et al. 2020). Moreover, MCR02, together with Masson (2000) and Kusaka et al. (2001), generated the need for detailed urban morphological input data, which later triggered important projects such as the World Urban Database Access Portal Tool (Ching et al. 2018) that contribute significantly to the advancement of urban climatology. 


\section{References}

Baldocchi DD (2013) A brief history on eddy covariance flux measurements: a personal perspective. Flux Letter 5(2):1-8

Baldocchi DD, Falge E, Gu L, Olson R, Hollinger D, Running S, Anthoni P, Bernhofer C, Davis K, Evans R, Fuentes J, Goldstein A, Katul G, Law B, Lee X, Malhi Y, Meyers T, Munger W, Oechel W, Paw UKT, Pilegaard K, Schmid HP, Valentini R, Verma S, Vesala T, Wilson K, Wofsy S (2001) Fluxnet: A new tool to study the temporal and spatial variability of ecosystem-scale carbon dioxide, water vapor, and energy flux densities. Bull Am Meteorol Soc 82:2415-2434

Beljaars ACM, Viterbo P (1998) Role of the boundary layer in a numerical weather prediction model. In: Holtslag AAM, Duynkerke PG (eds) Clear and cloudy boundary layers. Royal Netherlands Academy of Arts and Sciences, Amsterdam, pp 287-304

Betts AK (1973) Non-precipitating cumulus convection and its parameterization. Q J R Meteorol Soc 99:178-196

Bornstein RD (1975) The two-dimensional URBMET urban boundary layer model. J Appl Meteorol $14: 1459-1477$

Bougeault P, Lacarrere P (1989) Parameterization of orography-induced turbulence in a mesobeta-scale model. Mon Weather Rev 117(8):1872-1890

Bueno B, Pigeon G, Norford LK, Zibouche K, Marchadier C (2012) Development and evaluation of a building energy model integrated in the TEB scheme. Geosci Model Dev 5(2):433-448

Businger JA (1988) A note on the Businger-Dyer profiles. Boundary-Layer Meteorol 42:145-151

Businger JA, Wyngaard JC, Izumi Y, Bradley EF (1971) Flux-profile relationships in the atmospheric surface layer. J Atmos Sci 28:181-189

Chen F, Dudhia J (2001) Coupling an advanced land surface-hydrology model with the Penn State-NCAR MM5 modeling system. Part I: model implementation and sensitivity. Mon Weather Rev 129:569-585

Chen F, Kusaka H, Bornstein R, Ching J, Grimmond S, Grossman-Clarke S, Loridan T, Manning KW, Martilli A, Miao S (2011) The integrated WRF/urban modeling system: development, evaluation, and applications to urban environmental problems. Int J Climatol 31(2):273-288

Ching J, Mills G, Bechtel B, See L, Feddema J, Wang X, Ren C, Brousse O, Martilli A, Neophytou M, Mouzourides P, Stewart I, Hanna A, Ng E, Foley M, Alexander P, Aliaga D, Niyogi D, Shreevastava A, Bhalachandran P, Masson V, Hidalgo J, Fung J, Andrade M, Baklanov A, Dai W, Milcinski G, Demuzere M, Brunsell N, Pesaresi M, Miao S, Mu Q, Chen F, Theeuwes N (2018) World Urban Database and Access Portal Tools (WUDAPT), an urban weather, climate and environmental modeling infrastructure for the Anthropocene. Bull Am Metereol Soc 99:1907-1924

De Munck C, Lemonsu A, Bouzouidja R, Masson V, Claverie R (2013) The GREENROOF module (v7.3) for modelling green roof hydrological and energetic performances within TEB. Geosci Model Dev 6:1941-1960

Deardorff JW (1966) The counter-gradient heat flux in the lower atmosphere and in the laboratory. J Atmos Sci 23:503-506

Deardorff JW (1972) Numerical investigation of neutral and unstable planetary boundary layers. J Atmos Sci 29:91-115

Deardorff JW (1976a) Entrainment rate of stratocumulus topped mixed layer. Q J R Meteorol Soc 102:563-582

Deardorff JW (1976b) Usefulness of liquid-water potential temperature in a shallow-cloud model. J Appl Meteorol 15:98-102

Deardorff JW (1980) Stratocumulus-capped mixed layers derived from a three-dimensional model. BoundaryLayer Meteorol 18:495-527 (D80)

Dyer AJ (1967) The turbulent transport of heat and water vapour in an unstable atmosphere. Q J R Meteorol Soc 93(398):501-508

Dyer AJ (1974) A review of flux-profile relationships. Boundary-Layer Meteorol 7(3):363-372

Dyer AJ, Hicks BB (1970) Flux-gradient relationships in the constant flux layer. Q J R Meteorol Soc 96(410):715-721

Ek MB, Holtslag AAM (2004) Influence of soil moisture on boundary layer cloud development. J Hydrometeor 5:86-99

Eugster W, Senn W (1995) A cospectral correction for measurement of turbulent NO2 flux. Boundary-Layer Meteorol 74:321-340

Fairall CW, Bradley EF, Rogers DP, Edson JB, Young GS (1996) Bulk parameterization of air-sea fluxes for Tropical Ocean-Global Atmosphere Coupled-Ocean Atmosphere Response Experiment. J Geophys Res 101(C2):3747-3764

Finnigan JJ (2004) A re-evaluation of long-term flux measurement techniques part II: coordinate systems. Boundary-Layer Meteorol 113:1-41 (FP2) 
Finnigan JJ, Clement R, Malhi Y, Leuning R, Cleugh HA (2003) A re-evaluation of long-term flux measurement techniques part I: averaging and coordinate rotation. Boundary-Layer Meteorol 107:1-48 (FP1)

Frech M, Mahrt L (1995) A two-scale mixing formulation for the atmospheric boundary layer. Boundar-Layer Meteorol 73:91-104

Garuma GF (2018) Review of urban surface parameterizations for numerical climate models. Urban Clim 24:830-851

Grachev AA, Andreas EL, Fairall CW, Guest PS, Persson POG (2013) The critical Richardson number and limits of applicability of local similarity theory in the stable boundary layer. Boundary-Layer Meteorol 147:51-82

Gurvich AS (1962) Spectry pulsacii vertikalnoj komponenty skorosti vetra i ich svjazi s mikrometeorologitcheskimi uslovijach (Spectra of the fluctuations of the vertical wind component and the connection to micrometeorological conditions). Atmos Turb Trudy inst fiziki atmos AN SSSR 4:101-136

Hicks BB (1972) Propeller anemometers as sensors of atmospheric turbulence. Boundary-Layer Meteorol 3:214-228

Hicks BB (1976) Wind profile relationships from the 'Wangara' experiment. Q J R Meteorol Soc 102:535-551

Högström U (1988) Non-dimensional wind and temperature profiles in the atmospheric surface layer: a reevaluation. Boundary-Layer Meteorol 42:55-78

Holtslag AAM, Boville BA (1993) Local versus nonlocal boundary-layer diffusion in a global climate model. J Clim 6:1825-1842

Holtslag AAM, Moeng C-H (1991) Eddy diffusivity and counter-gradient transport in the convective atmospheric boundary layer. J Atmos Sci 48:1690-1698

Holtslag AAM, de Bruijn EIF, Pan HL (1990) A high-resolution air mass transformation model for short range weather forecasting. Mon Weather Rev 118:1561-1575

Holtslag AAM, Svensson G, Baas P, Basu S, Beare B, Beljaars ACM, Bosveld FC, Cuxart J, Lindvall J, Steeneveld GJ, Tjernström M (2013) Stable atmospheric boundary layers and diurnal cycles: challenges for weather and climate models. Bull Am Meteorol Soc 94:1691-1706

Hong S-Y, Pan H-L (1996) Nonlocal boundary layer vertical diffusion in a Medium-Range Forecast model. Mon Weather Rev 124:2322-2339

Hong S, Noh Y, Dudhia J (2006) A new vertical diffusion package with an explicit treatment of entrainment processes. Mon Weather Rev 134:2318-2341

Horst TW (1973) Spectral transfer functions for a three component sonic-anemometer. J Appl Meteorol 12:1072-1075

Horst TW (1997) A simple formula for attenuation of eddy fluxes measured with first-order-response scalar sensors. Boundary-Layer Meteorol 82:219-233

Joe P, Belair S, Bernier NB, Bouchet V, Brook JR, Brunet D, Burrows W, Charland J-P, Dehghan A, Driedger N, Duhaime C, Evans G, Filion A-B, Frenette R, de Grandpré J, Gultepe I, Henderson D, Herdt A, Hilker N, Huang L, Hung E, Isaac G, Jeong C-H, Johnston D, Klaasen J, Leroyer S, Lin H, MacDonald M, MacPhee J, Mariani Z, Munoz T, Reid J, Robichaud A, Rochon Y, Shairsingh K, Sills D, Spacek L, Stroud C, Su Y, Taylor N, Vanos J, Voogt J, Wang JM, Wiechers T, Wren S, Yang H, Yip T (2018) The environment canada pan and Parapan American science showcase project. Bull Am Meteorol Soc 99:921-953

Kaimal JC, Wyngaard JC, Izumi Y, Coté OR (1972) Spectral characteristics of surface layer turbulence. Q J R Meteorol Soc 98:563-589

Krayenhoff ES, Crawford B, Martilli A, Oke T, Stastny A, Nazarian N, Giometto M, Bailey B, Jiang T, Christen A, Voogt J (2020) A multi-layer urban canopy meteorological model with trees (BEP-Tree): street tree impacts on pedestrian-level climate. Urban Clim 32:100590

Kristensen L, Jensen NO (1979) Lateral coherence in isotropic turbulence and in the natural wind. BoundaryLayer Meteorol 17:353-373

Kusaka H, Kimura F, Hirakuchi H, Mizutori M (1999) Application of a simple parameterization of urban canopy layer to a mesoscale model. In: Proc Meteorol Soc Japan, 1999 Autumn Meeting, Fukuoka, p.74 (in Japanese)

Kusaka H, Kondo H, Kikegawa Y, Kimura F (2001) A simple single-layer urban canopy model for atmospheric models: comparison with multi-layer and slab models. Boundary-Layer Meteorol 101:329-358 (K4-01)

Kusaka H, Chen F, Tewari M, Hirakuchi H (2005) Impact of the urban canopy model in the next-generation numerical weather prediction model WRF. Environ Syst Res 33:159-164 (in Japanese)

Laaidi K, Zeghnoun A, Dousset B, Bretin P, Vandentorren S, Giraudet E, Beaudeau P (2012) The impact of heat islands on mortality in Paris during the August 2003 heat wave. Environ Health Perspect 120(2):254-259

Lee X (1998) On micrometeorological observations of surface-air exchange over tall vegetation. Agric For Meteorol 91:39-49 
Lee X (1999) Reply to comment by Finnigan on "On micrometeorological observations of surface-air exchange over tall vegetation". Agric Forest Meteorol 97:65-67

Lee X, Massman W, Law B (eds) (2004) Handbook of micrometeorology: a guide for surface flux measurement and analysis, vol 29. Springer, Berlin

LeMone M, Angevine W, Bretherton C, Dudhia J, Fedorovich E, Katsaros K, Lenschow D, Mahrt L, Patton E, Sun J, Tjernström M, Weil J (2019) 100 years of progress in boundary-layer meteorology. Meteorol Monogr. https://doi.org/10.1175/AMSMONOGRAPHS-D-18-0013.1

Lemonsu A, Masson V, Shashua-Bar L, Erell E, Pearlmutter D (2012) Inclusion of vegetation in the Town Energy Balance model for modeling urban green areas. Geosci Model Devel 5:1377-1393

Lilly DK (1968) Models of cloud-topped mixed layers under a strong inversion. Q J R Meteorol Soc 94:292-309

Lock AP, Brown AR, Bush MR, Martin GM, Smith RN (2000) A new boundary layer mixing scheme. Part I: scheme description and single-column model tests. Mon Weather Rev 128:3187-3199

Louis JF (1979) A parametric model of vertical eddy fluxes in the atmosphere. Boundary-Layer Meteorol 17:187-202 (L79)

Mahrt L (2011) The near-calm stable boundary layer. Boundary- Layer Meteorol 140:343-360

Martilli A, Clappier A, Rotach MW (2002) An urban surface exchange parameterisation for mesoscale models. Boundary-Layer Meteorol 104:261-304 (MCR02)

Masson V (2000) A physically-based scheme for the urban energy budget in atmospheric models. BoundaryLayer Meteorol 94:357-397 (M2000)

McMillen RT (1988) An eddy correlation technique with extended applicability to non-simple terrain. Boundary-Layer Meteorol 43:231-245

Moeng C-H, Sullivan PP (2015) Large eddy simulation. In: North G, Pylie J, Zhang F (eds) Encyclopedia of atmospheric science, vol 4. Academic Press, Cambridge, pp 232-240

Moncrieff JB, Massheder JM, DeBruin H, Elbers J, Friborg T, Heusinkveld B, Kabat P, Scott S, Søgaard H, Verhoef A (1997) A system to measure surface fluxes of momentum, sensible heat, water vapor and carbon dioxide. J Hydrol 188-189:589-611

Moore CJ (1986) Frequency response corrections for eddy correlation systems. Boundary-Layer Meteorol 37:17-35 (M86)

O'Brien JJ (1970) A note on the vertical structure of the eddy exchange coefficient in the planetary boundary layer. J Atmos Sci 27:1213-1215

Oke TR (1982) The energetic basis of the urban heat island. Q J R Meteorol Soc 108(455):1-24

Oke TR (1988) The urban energy balance. Prog Phys Geogr Earth Environ 12:471-508

Pan H-L, Mahrt L (1987) Interaction between soil hydrology and boundary-layer development. BoundaryLayer Meteorol 38:185-202

Panofsky HA (1963) Determination of stress from wind and temperature measurements. Q J R Meteorol Soc 89:85-94

Paw UKT, Baldocchi DD, Meyers TP, Wilson KB (2000) Correction of eddy-covariance measurements incorporating both advective effects and density fluxes. Boundary- Layer Meteorol 97:487-511

Pigeon G, Zibouche K, Bueno B, Le Bras J, Masson V (2014) Evaluation of building energy simulations with the TEB model against EnergyPlus for a set of representative buildings in Paris. Energy Bull 76:1-14

Redon E, Lemonsu A, Masson V, Morille B, Musy M (2017) Implementation of street trees in solar radiative exchange parameterization of TEB in SURFEX v8.0. Geosci Model Dev 10:385-411

Rotach MW (1993) Turbulence close to a rough urban surface part I: Reynolds stress. Boundary-Layer Meteorol 65:1-28

Salamanca F, Krpo A, Martillo A, Clappier A (2010) A new building energy model coupled with an urban canopy parameterization for urban climate simulations-part I. Formulation, verification and sensitivity analysis of the model. Theor App Climatol 99:331-344

Sandu I, Beljaars A, Bechtold P, Mauritsen T, Balsamo G (2013) Why is it so difficult to represent stably stratified conditions in numerical weather prediction (NWP) models? J Adv Model Earth Syst 5:117-133

Schoetter R, Masson V, Bourgeois A, Pellegrino M, Lévy J-P (2017) Parametrisation of the variety of human behaviour related to building energy consumption in TEB (SURFEX v. 8.2). Geosci Model Devel 10:2801-2831

Shuttleworth WJ, McNeil DD, Moore CJ (1982) A switched continuous-wave sonic anemometer for measuring surface heat fluxes. Boundary-Layer Meteorol 23:425-448

Sommeria G (1976) Three-dimensional simulation of turbulent processes in an undisturbed trade wind boundary layer. J Atmos Sci 33:216-241

Sommeria G, Deardorff JW (1977) Subgrid-scale condensation in models of nonprecipitating clouds. J Atmos Sci 34:344-355

Swinbank WC (1964) The exponential wind profile. Q J R Meteorol Soc 90:119-135 
Tans PP, Fung IY, Takahashi T (1990) Observational contrains on the global atmospheric CO2 budget. Science 247:1431-1438

Troen I, Mahrt L (1986) A simple model of the atmospheric boundary layer; sensitivity to surface evaporation. Boundary-Layer Meteorol 37:129-148 (TM86)

Webb EK (1970) Profile relationships: the log-linear range, and extension to strong stability. Q J R Meteorol Soc 96:67-90

Webb EK, Pearman GI, Leuning R (1980) Correction of flux measurements for density effects due to heat and water vapour transfer. Q J R Meteorol Soc 106:85-100

Wieringa J (1980) A reevaluation of the Kansas mast influence on measurements of stress and cup anemometer overspeeding. Boundary-Layer Meteorol 18:411-430

Wilczak JM, Oncley SP, Stage SA (2001) Sonic anemometer tilt-correction algorithms. Boundary-Layer Meteorol 99:127-150 (WSS01 and WOS01)

Zilitinkevich SS, Chalikov DV (1968) Determining the universal wind-velocity and temperature profiles in the atmospheric boundary layer. Izvestiya, Acad Sci USSR. Atmos Oceanic Phys 4:165-170 (English Edition)

Publisher's Note Springer Nature remains neutral with regard to jurisdictional claims in published maps and institutional affiliations. 